\title{
Chapter 5 \\ Building Teacher Capacity \\ at the Telangana Social Welfare \\ Residential Educational Institution \\ Society
}

\section{Tanya Kant, Aditi Nangia, Usha Nikita Satish and Aarya Shinde}

\begin{abstract}
In this chapter, we explore the effects of teacher professional development on student achievement at a high-performing public school network in Telangana, India. The school network is the Telangana Social Welfare Residential Educational Institutions Society (TSWREIS). The aim of TSWREIS is to address some of the challenges that students from marginalized castes face when obtaining an education. Our examination of this school network will include an overview of the current public education system in India, caste-based discrimination, program description, teacher and principal development description, and the integration of twenty-first century skills into the school network's curriculum. These core components highlight what makes TSWREIS successful in its mission to provide a quality education to marginalized students. A concluding section discusses the key enablers of that allow the project to have stable leadership and a sharp focus on their vision and goals, rather than the instability that reforms sometime face because of change in leadership.
\end{abstract}

\subsection{Introduction}

In this chapter, we will examine a network of social welfare schools in Telangana, India, paying close attention to the effects of teacher professional development on student outcomes. The school system that we analyze is the Telangana Social Welfare Residential Educational Institutions Society (TSWREIS). This school system aims to address the education inequality faced by millions of Indians due to caste-based discrimination. The network emerged in response to the failure of the public education sector in Andhra Pradesh, the state in which Telangana originated, to offer adequate educational opportunities to children from lower castes. TSWREIS is thus focused on providing such high-quality educational opportunities to students from marginalized communities in Telangana, India.

T. Kant $(\varangle) \cdot$ A. Nangia $\cdot$ U. N. Satish $\cdot$ A. Shinde

52 Dover Street, Somerville, MA 02144, USA

e-mail: tanyakant@gse.harvard.edu

(C) The Author(s) 2020

F. M. Reimers (ed.), Empowering Teachers to Build a Better World,

SpringerBriefs in Education, https://doi.org/10.1007/978-981-15-2137-9_5 
We begin our analysis by first providing social and political context of India and an overview of the education landscape in Telangana. We then describe the core elements of the TSWREIS model as well as the school network's theory of change that undergirds its approach to teacher professional development. We also focus on how teacher and school leadership development contributes to the success of the TSWREIS model. We conclude with key lessons learned from the analysis of this reform and its components.

\subsection{Public Education in India}

The Indian public school system educates over 12 million students of different faiths, beliefs and socio-economic status, making it one of the largest and most diverse school systems in the world. Over the last two decades, the public school system in India has expanded rapidly with policies like the Right to Free and Compulsory Education Act (RTE, 2009), which ensured that children, regardless of socio-economic status, are able to attend public schools for free.

However, the progress made on expanding access to education has not been matched in the improvement of the quality of education being provided. Public schools across India still struggle to meet the infrastructural criteria specified in the RTE, with many schools still not having regular access to fresh drinking water, functional toilets or running electricity. These roadblocks have negative implications on student learning and student performance. On top of these challenges, certain groups of students within the system also face the burden of caste-based discrimination.

\subsection{Understanding Caste-Based Discrimination}

The caste system in India distinguishes people within the Hindu society into four categories based on occupation and social status. Ascription to a particular caste is hereditary and cannot be changed as a result of the desires, effort or ability of an individual. Because occupation is related to membership in a particular caste, the system has historically limited access to jobs and other development opportunities for members of the lower castes. Until a couple of decades ago, lower caste or the shudras and the dalits lived in the periphery of cities or villages without access to basic human or education rights.

In attempts to make amends and redress the inequalities caused by the caste system, the Indian Constitution outlawed caste-based discrimination and launched India's affirmative action program in 1950. This program reserved seats in the legislature, government jobs and in public higher education institutions to increase participation from individuals from marginalized communities, which were re-grouped as Scheduled Castes (SC), Scheduled Tribes (ST) and Other Backward Classes (OBC). While this bill improved access for some members of these communities, the stigma 
associated with lower castes was not eliminated. Thus, caste-based discrimination still prevailed in overt and covert ways, often manifesting itself in the form of barriers to basic education and equal employment opportunities.

\subsection{Inception of TSWREIS}

As a response to the prevalent inequalities based on social classes in the society, in 1984, a network of social welfare schools was established in Andhra Pradesh to provide free, high-quality residential education to students belonging to the SC, ST and OBC. The creation of such a space for minority communities in the state was led by S. R. Sankaran, a bureaucrat in the Indian Administrative Services who established the Andhra Pradesh Social Welfare Residential Schools and promoted policies that empowered the SC community. At a time when the Indian government had made limited efforts to increase enrolment in public schools, the establishment of these schools ensured that students from SC, ST and OBC communities had access to free, good quality education from grades fifth through twelfth. (TSWREIS Note 2, 2018).

A significant shift in the system occurred in 2014 when the state of Telangana splintered from Andhra Pradesh, which caused the existing network of social welfare schools to split, giving rise to the Telangana Social Welfare schools (TSWREIS) as a separate entity. The social welfare schools in Telangana came under the leadership of Dr. R. S. Praveen Kumar, a bureaucrat with the Indian Police Services, who became the Secretary of the TSWREIS network and steered the institution toward innovation, excellence and improved accountability. Before assuming his role as the Secretary, Dr. Kumar had studied at the Kennedy School of Government at Harvard University where he cross-registered ed in a course on comparative education policy at the Harvard Graduate School of Education. His education at the Harvard Kennedy School inspired him to employ diverse strategies to improve the social welfare schools.

A key factor that aided initial progress within the TSWREIS system was governmental support. In the newly formed state of Telangana, Chief Minister K. Chandrasekhar Rao supported the expansion of social welfare schools and supported the opening of 103 social welfare schools and 30 residential degree colleges for women in the academic year 2016-2017. As a result of such support, as of 2019, TSWREIS runs 268 residential educational institutions from grade five to undergraduate level in Telangana and caters to almost one hundred and thirty thousand students from the SC community. This level of outreach has ensured that over the last three decades, students from the SC community, who would have earlier not attended school or attended schools without basic facilities, now have the opportunity to access good quality schooling. The TSWREIS network is also supported by the Ministry of Scheduled Caste Development in Telangana which provides essential support in terms of funding and resources to allow the school network to expand. By 2022, the network hopes to enroll one million students in the social welfare schools across Telangana (P. Kumar, personal communication, Dec. 04, 2018). 


\subsection{Theory of Change}

In the following section, we analyze the internal coherence of the TSWREIS model by evaluating its theory of change using Carol Weiss' framework, as explained in the working paper compiled by McCoy and Schindler (2017). The analysis will focus on four key areas: ultimate outcomes, intervention activities, mediating processes and moderators.

\subsubsection{Ultimate Outcomes}

The TSWREIS schools have a clear vision to develop an institution that can impart quality education to students belonging to marginalized communities in order to promote equality of choice and opportunities.

\subsubsection{Intervention Activities}

One of the key strengths of the TSWREIS system is the focus on improving the performance of the different actors composing the school system. Over the last six years, they have progressively improved their interventions for teachers, students and principals and have partnered with multiple external organizations, which is a practice that is still gaining momentum in the rest of the government school systems across the country. Their focus on improving the school network is evident in their efforts to build the capacity of their teachers and principals while seeking support from external organizations that are experts in their fields.

Their intervention activities for teacher training and development constitute preservice and in-service training of teachers. While the pre-service training runs for ten days, the in-service training component is delivered over the course of an academic year. The second type of intervention activity is professional development for school leaders. Over the last three years, several cohorts of principals have undergone training and coaching in key aspects of instructional leadership provided by India School Leadership Institute (ISLI), a non-governmental organization that aims to build capacity and develop strategies for improving student learning outcomes and overall school performance. Another type of intervention is parental engagement and collaboration. The school system provides multiple opportunities for parents to be involved in their children's education, such as having an open channel for parents and teachers to share information and concerns and having programs like home visits by teachers to maintain strong community engagement, even when the parents live far away.

The last intervention that leaves an impact on the quality of education provided in these schools is the curriculum design for the school network. While the academic 
curriculum being followed in the schools is the same as that in the rest of the state (Andhra Pradesh State Curriculum), the TSWREIS model has additional provisions in terms of co-curricular activities and opportunities to promote whole-child development. This intervention has increased students' learning time beyond school hours and provides students with the opportunities for physical and co-curricular activities, both before and after school, and during the summer vacation in an attempt to provide students with a holistic education.

\subsubsection{Mediating Process}

For teacher preparation, the mediating process supporting the intervention includes different levels of strategy meetings that are held throughout the academic year to promote information exchange between the leadership and the teaching staff. For principal development, the accompanying mediating processes consist of the training sessions led by representatives from ISLI, along with monthly inspections and monitoring by regional coordinators. To improve the instructional leadership capacity within the school network, the schools have partnered with Aavishkaar, an organization that improves teacher knowledge and pedagogy for teaching conceptual math and science lessons. For parental engagement, the supplementing mediating processes include efforts such as end-of semester home visits as part of the QUEST initiative, which provides a platform for the teachers to share progress reports with parents. Another set of mediating process that is put in place to enhance stakeholder engagement is the interaction camp that is organized to initiate discussions on the art of effective parenting and opportunities available for their students to explore after school, among other topics of discussion.

\subsubsection{Moderators}

Some of the key moderators that enable the TSWREIS system to function effectively stem from the very design of the initiative. Since the TSWREIS schools are residential in nature, the first benefit they gain is additional instruction time. Another resource that the school systems gain is in the form of additional funding, which comes in from both the state government and the Ministry of Scheduled Caste Development. The government spends approximately one lakh rupees (approximately fourteen hundred US dollars) per child per year (G. Varkey, personal communication, September $28,2018)$. This level of expenditure roughly matches the investment that an average middle-income family would make on private school education in the country. 


\subsubsection{Implicit Assumptions}

The TSWREIS model functions with several implicit assumptions about how the inputs it delivers produce the expected outputs. For instance, the teacher training and development model is based on the assumption that investing in teacher training modules will improve teacher knowledge. Similarly, implicit in the initiatives taken to build teacher-parent interactions is the assumption that regular discussion about student and school performance will help reduce information asymmetry, thereby promoting a culture of trust and collaboration between the parties.

The next section describes the intervention programs for teachers, principals and curriculum development in greater detail, along with a comparative analysis of TSWREIS' approach on each of these components with contemporary frameworks that outline a vision for strong teaching and school leadership. The section will also assess the impact of these programs on the larger TSWREIS school system and improvements in student outcomes.

\subsection{Program Description: Principal Development}

TSWREIS' principal recruitment, training and development are aimed at ensuring that principals are effective administrative leaders. The recruitment criteria require that the candidates have at least eight to ten years of teaching experience and the hiring takes place either from within the teaching staff or through external recruitment. The selected candidates are trained in school administration, school finance, record keeping and instructional expertise. The responsibilities of the principals on the ground are structured such that a majority of their time is spent on school administration, including duties such as monitoring student boarding and nutrition, data analysis for assessments, teacher development through meetings and observations, parent engagement and implementing programs as directed by TSWREIS office. They have opportunities to provide instructional inputs to the teachers; however, these are often generic and not subject-specific, given that they may not have advanced subject expertise required for coaches in grades ninth through twelfth. For this purpose, their work in instructional leadership is supported by regional coordinators. Overall, the tasks undertaken by the principals and vice-principals are heavily focused on administration, management and conducting the activities mentioned in the TSWREIS calendar of events, rather than being aligned to the students' reality and the school's vision and long-term goals (Telangana Social Welfare Residential Educational Institutions Society Calendar of Events, 2018).

In contrast, Singapore's Leaders in Education Program (LEP), which develops principals' abilities to create a strong school culture, navigates diversity in student demographics and works on hands-on projects. While the LEP empowers principals to be adaptable, flexible and helps them be ready to analyze the needs of the school and tailor national policies to the school's context, the TSWREIS training heavily 
focuses on the principal's abilities to implement the existing policies and less on the principal's ability to create a vision, build a collaborative teaching team and develop school development plans aligned to their schools needs and vision (Tan \& Low, 2018). Providing the TSWREIS principals with similar skills through training and coaching would enable them to identify needs of their schools, use data to inform instructional and administrative decisions at schools and align their school's activities with their school's context and vision. Once they are able to design interventions, monitor progress and facilitate effective trainings, they would have the autonomy to test solutions that work for their schools and make decisions supported by evidence.

\subsection{Program Description: Teachers}

Teacher development in TSWREIS includes both pre- and in-service training. Their pre-service teacher training focuses on improving pedagogy, understanding textbook philosophy, classroom management, effective communication in English, practical teaching experience with feedback and opportunities to build relationships with students and their families prior to the start of the school year. In-service training is delivered over the academic year and includes teacher seminars, regional trainings in innovative pedagogy, peer observations and weekly meetings to discuss focus areas for the school and attend master classes by senior teachers within the school and introduce best practices in their own teaching practice. The principals conduct weekly school team meetings to discuss problems faced by the teachers and brainstorm solutions for those problems.

The TSWREIS teacher training model builds upon the existing models of teacher preparation in the country, but areas of improvement have been identified and are being addressed through the New Quality Policy (NQP) introduced in 2016. The NQP includes guidelines to improve the structure of in-service training and teacher evaluation and seeks to empower teachers to help students develop twenty-first century skills and improve academic achievement among students. It introduced advanced pedagogical practices in the classroom, such as flipped classroom teaching and modular teaching (cross subject, theme-based teaching) and enables the teachers to realize their full potential through peer learning. The NQP also contains guidelines to assess teachers through regional seminars and provides support to struggling teachers through continuous guidance, mentorship and remedial training programs (New Quality Policy, 2016).

While some of TSWREIS' practices in teacher development compare well with widely known frameworks for effective teacher practices and models for teacher development, there are aspects that the NQP does not cover. The eight dimensions about teaching included in the World Bank's Systems Approach for Better Education Results (SABER) Teachers framework (Liang, Kidwai, \& Zhang, 2016) comprise setting clear expectations for teachers, attracting the best into teaching, preparing 
teachers with useful training and experience, matching teachers' skills with students' needs, leading teachers with strong principals, monitoring teaching and learning, supporting teachers to improve instruction and motivating teachers to perform. While some of these components exist in the NQP framework, some core elements still remain unaddressed. For instance, the components of NQP reward good performance, thereby motivating teachers in TSWREIS schools to perform consistently and strive to improve their teaching methods. Similarly, the pre-service and in-service teacher development framework also aligns with the third, fourth and eighth goals of the SABER-Teachers framework and ensures that teachers are empathetic toward their students. However, a major area that is not addressed is closely matching teacher skills with specific student needs. There is limited evidence to suggest that the teacher training model in place is adaptable to student outcomes in the classroom.

In addition, examining the teacher development model through the wide range of models presented in the comprehensive review of teacher professional development models: "Teacher Professional Development_an international review of the literature" by Villegas-Reimers (2003), we observe that TSWREIS uses observation of excellent practice, supervision, workshops and seminars for creating opportunities for vertical growth in their model. Investing substantial resources and efforts on teacher pedagogy has begun a move away from the prevalent practice of rote learning in the classroom. However, the existing practices can be improved further to include opportunities for skills development, reflection and case-based learning to help teachers understand the continuous and evolving vision for twenty-first century skills and receive the day-to-day support and coaching that can improve their instruction toward holistic student learning outcomes.

\subsection{Program Description: Integrated Curriculum}

In the National Research Council's report "Education for Life and Work: Developing Transferable Knowledge and Skills in the $21^{\text {st }}$ Century" James W. Pellegrino and Margaret L. Hilton categorize twenty-first century competencies into three major groups: cognitive competencies, intrapersonal competencies and interpersonal competencies, as described in the first chapter of this book. Some of the cognitive competencies include critical thinking, creativity, oral and written communication. Intrapersonal skills include cultural awareness and competence, initiative, citizenship and career orientation among others. Interpersonal skills include teamwork, negotiation, social influence and so on.

The Telangana State Curriculum Framework (TSCF) is similar to the Andhra Pradesh State Curriculum Framework (APSCF) created in 2011, which is based on suggestions from the National Curriculum Framework created in 2005. The state curriculum envisions that education will produce rational and responsible citizens who can appreciate their heritage and become agents of social change. Subjects taught include English, Mathematics, Science and Social Studies, Work Education, Art and Culture, Value Education and Life Skills, Information and Communications 
Technology, and Physical Education. These subjects identify learning goals as academic standards. Some of the academic standards are problem-solving, reasoningproof, appreciation and sensitivity, reading comprehension, information skills, citizenship, creativity, community service and interpersonal communication. Comparing the skills included in the Hilton-Pellegrino framework with those included in the TSCF, we observed that the TSCF covers 75 percent of the skills in the cognitive domain but only 50-60 percent of the competencies in the interpersonal and intrapersonal domains. The curriculum has a stronger focus on traditional academics and a thin emphasis on twenty-first century skills, such as taking initiative, meta-cognition and self-regulation.

Although the TSCF does not include many of the skills required for living and working in the twenty-first century, TSWREIS conducts activities beyond regular school hours and over the summer vacation to ensure that students do have opportunities to develop these skills. For instance, the development of strong language and communication skills is promoted through English-Plus and Writing-Plus clubs that provide an exploratory space for the students to independently familiarize themselves with the English language. Their early foundation program for classes fifth and sixth is developed in collaboration with an external partner, Karadi Path, to help new students gain English language skills through songs, stories and other audio-visual resources. These have helped to improve academic performance within the school. There are also extracurricular activities that ensure that students develop different life skills. Some of these programs include the Ignite initiative and the annual Science Fair, which gives the students a chance to showcase their learning in widely attended student conference. The schools also have initiatives such as the Green Gurus program and the S. R. Sankaran super lectures, which encourage students to collaborate, refine their communication skills and earn extra money by teaching their peers. They have partnered with external organizations, such as Design for Change, an online platform that promotes practical application of learning and civic engagement by giving the students a chance to create innovative solutions for immediate problems faced in the world (Telangana Social Welfare Residential Educational Institutions Society Calendar of Events, 2018).

Additionally, an annual summer camp project was conceived in 2011 with the objective of giving the students a chance to engage with a range of academic, non-academic and athletic opportunities in order to identify their areas of interest. Between 2011 and 2018, the camp grew in size and quality, from ten camps and eight thousand students to reaching over forty thousand (G. Varkey, email communication, November 30, 2018).

Although preliminary analysis suggests that the TSCF and the additional activities conducted by TSWREIS cover most of the skills in the Hilton-Pellegrino framework, the efforts to inculcate twenty-first century skills are dispersed and in silos. In order to support students in developing a strong foundation of twenty-first century skills, targeted efforts need to be directed toward infusing opportunities to develop these skills in everyday teaching practice inside the classroom and in the extended learning hours. 


\subsection{Key Enablers}

As a chairman of TSWREIS, the Minister of the Scheduled Caste Development heads the society and has the authority to sanction funding for new ideas within the project. The in-built supportive structure helps by reducing the number of stakeholders involved in decision-making and supporting the implementation of new ideas and projects. Most bureaucrats in India are given fixed term appointments to positions at the secretary level, sometimes switching departments after just two years. The long-term appointment of Dr. Kumar as the Secretary of TSWREIS has enabled the project to have stable leadership and a sharp focus on their vision and goals, rather than the instability that changes in leadership can cause.

Another factor that has supported the reform is the staff structure. TSWREIS staff can be categorized into two levels: leadership and school staff. Their leadership team includes regional coordinators, school principals, and senior and junior viceprincipals. The teachers in the school, based on their experience and the grades they teach, can be categorized as senior teachers and junior teachers. The school structure enables junior teachers to be mentored by senior teachers through master lessons, classroom observations and feedback. Teachers' welfare is also taken care of by the teacher union. The teacher union under TSWREIS is a democratically elected body that consists of senior teachers and is registered with the government. According to Mr. George Varkey, a TSWREIS official involved in teacher training and development, like most teacher unions, they resisted the innovative practices and changes in teacher training when TSWREIS started to make changes to their program. However, they soon realized that the changes were beneficial to the students and helped achieve TSWREIS' vision. They now function as a cooperative body that works together with the management toward the common goal of improving student outcomes.

Another key strength of the TSWREIS model is having spaces for the different stakeholders to collaborate, both within the school system and outside. We examine these partnerships on two levels: internal capacity partnerships and external capacity partnerships. Within the school system, a collaboration between the school leadership and the teachers is promoted through weekly T-plus meetings, which ensure that the teachers are given the chance to discuss success any challenges faced through the week with the principals. This ensures that the school administration and the school staff are on the same page with regards to issues related to school improvement and key decisions within the school. Collaboration between the teachers is promoted through strategy meetings, held at the beginning of every week. During these meetings, experienced teachers demonstrate model lessons across several topics for the newer teachers on the payroll. After a week, the roles are flipped as the newer teachers apply the planning and execution strategies observed previously into a sample lesson. There is a constant feedback chain maintained throughout the process, which helps to identify the need for remedial training (G. Varkey, personal communication, September 28, 2018). 
Another important component within the internal capacity partnerships is the interaction between parents and teachers. Since the schools also operate as residential institutions, great emphasis is placed on ensuring that the teachers understand the context of the students in order to provide the required personal and emotional support. To achieve this, collaboration between teachers and parents is promoted through home visits that the teachers have to undertake after the end of each term, in order to understand the challenges that the students might be facing at home. These meetings also work to improve the levels of trust between the parents and the teachers (Telangana Social Welfare Residential Educational Institutions Society Calendar of Events, 2018). Their internal feedback mechanisms, which include video conferences between principals and the secretary and student councils and the secretary, enable regular evaluation of school-level programs and give students a chance to share some school-level feedback with the Secretary.

In terms of external partnerships, the TSWREIS schools collaborate with several organizations working in areas such as teacher training, school leadership development and curriculum design to leverage specialized support to supplement the state's efforts. For instance, two key partnerships developed to support teacher training include those with Russell's Spoken English and Aavishkaar. The former initiative is undertaken to equip the teachers with strong English language and communication skills, which is reflective of the core emphasis placed on English communication component for the students. The second partnership with Aavishkaar, a non-governmental organization that develops interactive methods to impart science and math education, has been initiated since the summer of 2018 to equip the teachers with varied skills to teach science and math for grades six and above (Telangana Social Welfare Residential Educational Institutions Society Calendar of Events, 2018). Parallel to the partnerships developed for teacher training, the TSWREIS schools also collaborate with ISLI. This is a stepping-stone to expand the role of the school leaders within the TSWREIS system beyond the traditional role of school principals and vice-principals focusing exclusively on administration.

\subsection{School Evaluations}

School evaluations are the key in assessing whether the school is functioning up to the standards mentioned in the reform. The Central Board of Secondary Education, India (CBSE) conducted an evaluation of the schools managed by TSWREIS. The CBSE rating has three levels: emergent, satisfactory and good. While there is merit in having a multileveled evaluation model, the CBSE has not generated a robust rubric that indicates what makes a school emergent, satisfactory or good. The CBSE has seven performance standards that are used to assess the rating of a school, which are outlined below and were used for evaluating the schools.

The CBSE uses seven performance standards in their evaluation. These performance standards include: PS1—academic outcomes, PS2-personal and social outcomes, PS3 — teaching, learning and assessments, PS4 - academic, co-academic 
and extracurricular inputs, PS5-health, safety, protection and guidance, PS6infrastructure and PS7-leadership. This evaluation was conducted for all schools, according to their districts.

We notice that most of these schools performed between the range of emergent to good, with an external evaluation rating as "emergent" and self-evaluation rating as "satisfactory". The four school reports reviewed by us indicate that those TSWREIS score the best on "personal and social outcomes of students" and were satisfactory in providing academic, co-academic and extracurricular inputs to students. The difference in the ratings leads us to question the process of evaluation. We notice that the assessment used by CBSE is not a standardized assessment and does not norm on specific criteria. For example, schools with tenth-grade passing rates of 96 and 60 percent are both given the same accreditation under academic outcomes. Similarly, in many sections of the report, it is unclear what weight is given to various factors in assigning a ranking. Thus, even though evaluations have been conducted, there is no standardized assessment with clear guidance on areas of excellence and areas of growth for the schools (Assessment and Accreditation Report, 2016-17).

Since there is no assessment of the reform yet, we can look at other results as indicators of success of the reform. According to Dr. Kumar, six schools which are part of TSWREIS won national-level awards in the national Design for Change competition. Several students have successfully secured admissions in prestigious institutes in India and internationally, in the fields of law, engineering, humanities and science (Telangana Social Welfare Residential Educational Institutions Society Calendar of Events, 2018). TSWREIS students have also performed well in sports, securing medals in national and international level championships for karate, chess, handball and regatta and scaling Mt. Renock as a group (Scaling Mount Renock, 2016). Therefore, we see some evidence of success of the reform in ways that are not captured entirely through the external evaluation produced by the CBSE.

Lastly, a way to identify if the intended outcomes are being achieved is to analyze results against the theory of change of the reform. It is clear that due to the opportunities provided by TSWREIS, several students from marginalized communities have been academically successful. However, the success of TSWREIS should not depend on a single structure or leader and should be sustainable in the way that these sections of the society can create this change for themselves.

\subsection{Lessons Learned}

The TSWREIS schools have significantly improved student outcomes in comparison to the public schools which exist across the rest of the state. However, there are several areas where the school system can be further refined and strengthened. These are discussed in four broad areas below. 


\subsubsection{Teachers}

While the TSWREIS model has established a functional base for teacher training, there is room for improvement with respect to creating a strong vision for teacher professional development. In the current system, teachers have access to pre-service training and in-service training, but there is a lack of a cohesive developmental path for the teachers. There is also a lack of differentiation in training based on teachers' existing level of experience, interests and needs. A possible way of addressing this challenge is to have the school leaders create professional learning opportunities that align with the goals that teachers are working on every quarter. These goals should be assessed on a quarterly basis, so that school leaders can adjust the learning path based on progress made. Additionally, the training should differentiate between the specialized needs of teachers so that teachers of all levels of experience are trained in areas that allow them to grow as facilitators and leaders.

Another element in the current model that shows room for further growth is preparing the teachers to integrate twenty-first century skills into classroom instruction independently.

Throughout the school year, teachers do not have learning opportunities to develop the necessary skills for them to strategize closely based on the needs of their classrooms. For this, explicit training on how to integrate twenty-first century skills into the current curriculum is needed as part of the in-service or pre-service component, so that teachers are equipped to incorporate these skills into their teaching. This can ensure that inter and intrapersonal competencies are developed during class hours and afterwards in the activities that students participate in.

\subsubsection{School Leaders}

In terms of school leader preparation and support, due to the complex structure of the management team and the multiplicity of voices involved, principals and other higher officials make decisions. However, there is less autonomy for them to focus on certain aspects that align to their schools' needs and vision. Furthermore, school leaders are burdened with administrative responsibilities and hence cannot devote enough time to teacher growth and development or student outcomes. This leaves room for capacity building for the principals to prepare them to execute all aspects of their roles effectively and to build a strong school team culture that focuses on outcomes for all children. The administrative pressure on the principals can also be relieved by looking at hiring and training additional staff or temporary workers to manage operations. 


\subsubsection{Curriculum}

Even though the curriculum and the activities implemented by TSWREIS include most of the skills included in the Hilton-Pellegrino framework, the activities leading to these skills are not adding up to the goals of the reform. The inputs toward building twenty-first century skills can be streamlined through a curriculum sequence that describes the vision for mastery of the skills mentioned in the reform goals. Instead of the schools trying to focus on all skills at once, the skills can be sequenced in different grades. This would allow students to gain a wide range of skills with greater depth as they progress through school. This could also enable the teachers to implement twenty-first century skills more effectively in their lessons.

\subsubsection{System Level}

The TSWREIS model has scope to strengthen two of the four areas of systemwide alignment outlined in the World Development Report, 2018. These are unclear objectives and blurred responsibilities; lack of information and metrics and actor incentives. This could be addressed by promoting strategic planning that examines Strengths-Weakness-Opportunities-Threat for each school (including analysis of student assessment data). It could be supported further by aligning classroom and school-level activities to the school vision, defining clearer job roles with greater autonomy and professional development to decentralize some school-level decisions related to student learning, and providing non-monetary incentives to improve student outcomes in twenty-first century skills for teachers and students alike.

\subsection{Conclusion}

Overall, TSWREIS has gone against the grain in its efforts to provide quality education to students from marginalized communities in Telangana. The model has managed to increase the efficiency of the actors involved in the school system, such as the teaching staff and the school leaders, by reducing information asymmetry and promoting collaboration at several levels. This has resulted in notable improvements in student outcomes, which have allowed graduates from the TSWREIS system to access premier education institutions in the country. At the same time, the model can be refined further by ensuring that their curriculum framework and teacher training framework more intentionally adopt a twenty-first century and deeper learning approach. 


\section{References}

Andhra Pradesh State Curriculum Framework. (2011). Retrieved November 27, 2018, from https:// apscert.gov.in/frameworks.html.

Assessment and Accreditation Report-2016-17 TSWRS \& Jc. (2018). Retrieved October 5, 2018 from https://drive.google.com/drive/folders/1PY0in301ZDwBv2wZG1zyTYLCxz5nr8bM.

Information Under Section 4(1) (b) of RTI Act, 2005. (n.d.). Retrieved November 28, 2018, from https://www.tswreis.telangana.gov.in/RTI\%20Act\%20Aprl-2017.pdf.

Liang, X., Kidwai, H., \& Zhang, M. (2016). Systems approach to analyzing education policies and linking them to implementation and learning outcomes. In How Shanghai does it. Insights and lessons from the highest-ranking education system in the world. Retrieved from https:// openknowledge.worldbank.org/bitstream/handle/10986/24000/9781464807909.pdf.

McCoy, D. C. \& Schindler, H. (2017). Theories of change in education: A fresh look at a familiar tool. Working paper.

Mission. (n.d.). Retrieved September 18, 2018, from https://www.tswreis.telangana.gov.in/society_ internal/thegenesis.html

New Quality Policy. (2016). Retrieved November 28, 2018, from https://drive.google.com/drive/ folders/1PY0in301ZDwBv2wZG1zyTYLCxz5nr8bM

Pellegrino, J. W., \& Hilton, M. L. (Eds.). (2012). Education for life and work: developing transferable knowledge and skills in the 21st century. Washington, DC: The National Academic Press.

Scaling Mount Renock, a rare feat for this tribal girl (2016). The Hindu. Retrieved from https://www.thehindu.com/news/national/telangana/scaling-mount-renock-a-rare-feat-forthis-tribal-girl/article7985807.ece.

Tan, O. S., \& Low, E. (2018). Chapter 8. Working in times of uncertainty to prepare for the future: A study of Singapore's leaders in education program. In Reimers and Chung (Eds.), Preparing teachers to educate whole students (pp. 219-245) Cambridge, MA: Harvard Education Press.

Telangana Social Welfare Residential Educational Institutions Society Calendar of Events. (2018). Retrieved October 2, 2018, from https://drive.google.com/drive/folders/ 1PY0in301ZDwBv2wZG1zyTYLCxz5nr8bM

Teixeria, J. (2017, March 10). Why education infrastructure matters for learning. The World Bank. Retrieved December 03, 2018 from https://blogs.worldbank.org/education/why-educationinfrastructure-matters-learning.

TNN. (2016, May 10). 95\% Schools in Telangana headless: MHRD report. The Times of India, Business. Retrieved December 01, 2018, from https://timesofindia.indiatimes.com/city/hyderabad/95schools-in-Telangana-headless-MHRD-report/articleshow/52196634.cms.

TSWREIS Note 2. (2018). Retrieved December 05, 2018, from https://drive.google.com/drive/ folders/1PY0in301ZDwBv2wZG1zyTYLCxz5nr8bM.

Villegas-Reimers, E. (2003). Teacher professional development: An international review of the literature (Quality education for all). Paris: International Institute for Educational Planning. Retrieved October 20, 2018, from https://www.teachersity.org/files/PDF/UNESCO\%20$\% 20$ Teacher\%20Professional\%20Development.pdf.

World Bank. (2018). World development report 2018. Learning to realize education's promise. Retrieved October 23, 2018, from https://openknowledge.worldbank.org/handle/10986/28340.

Tanya Kant holds a Master's in International Education Policy from the Harvard Graduate School of Education. She also holds a B.A. in English Literature from Delhi University. She has served as a Teach for India Fellow from 2016 to 2018, and is passionate about using data to improve decision-making in school systems. 
Aditi Nangia works with the governance team of Central Square Foundation, a non-profit organization working with the vision of ensuring quality school education for all children in India. Aditi is interested in understanding market economies, incentives and improving school systems.

Usha Nikita Satish holds a Master's in International Education Policy from the Harvard Graduate School of Education. Usha is an education entrepreneur who plans to create a high-performing international network of schools that focuses on implementing a curriculum that teaches twentyfirst century skills. Usha's education career started out as a 2013 Teach for America Corps in Miami-Dade (TFA), she then went on to teach for 3 years at KIPP DC: College Prep for a total of 5 years of Teaching History and English.

Aarya Shinde holds a Master's degree from the Harvard Graduate School of Education, specializing in International Education Policy. She has explored roles related to teaching as well as school leadership, during her work with Teach for India from 2015 to 2018. She is interested in analyzing, designing and implementing customized education solutions through strategic solution.

Open Access This chapter is licensed under the terms of the Creative Commons Attribution 4.0 International License (http://creativecommons.org/licenses/by/4.0/), which permits use, sharing, adaptation, distribution and reproduction in any medium or format, as long as you give appropriate credit to the original author(s) and the source, provide a link to the Creative Commons license and indicate if changes were made.

The images or other third party material in this chapter are included in the chapter's Creative Commons license, unless indicated otherwise in a credit line to the material. If material is not included in the chapter's Creative Commons license and your intended use is not permitted by statutory regulation or exceeds the permitted use, you will need to obtain permission directly from the copyright holder. 